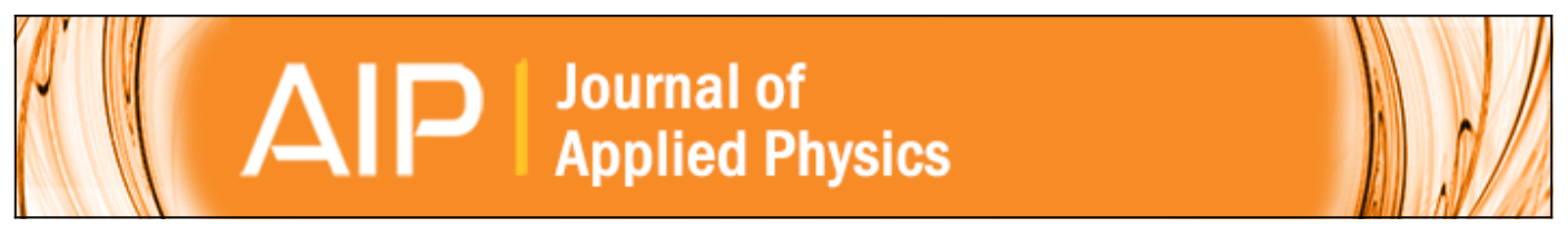

\title{
Differences in n-type doping efficiency between Al- and Ga-ZnO films
}

Mercedes Gabás, Angel Landa-Cánovas, José Luis Costa-Krämer, Fernando Agulló-Rueda, Agustín R.

González-Elipe, Pilar Díaz-Carrasco, Jorge Hernández-Moro, Israel Lorite, Pilar Herrero, Pedro Castillero, Angel

Barranco, and José Ramón Ramos-Barrado

Citation: Journal of Applied Physics 113, 163709 (2013); doi: 10.1063/1.4803063

View online: http://dx.doi.org/10.1063/1.4803063

View Table of Contents: http://scitation.aip.org/content/aip/journal/jap/113/16?ver=pdfcov

Published by the AIP Publishing

\section{Articles you may be interested in}

Radio-frequency superimposed direct current magnetron sputtered Ga:ZnO transparent conducting thin films J. Appl. Phys. 111, 093718 (2012); 10.1063/1.4709753

Compositional study of vacuum annealed $\mathrm{Al}$ doped $\mathrm{ZnO}$ thin films obtained by RF magnetron sputtering J. Vac. Sci. Technol. A 29, 051514 (2011); 10.1116/1.3624787

Combinatorial characterization of transparent conductive properties of Ga-doped ZnO films cosputtered from electron cyclotron resonance and rf magnetron plasma sources

J. Vac. Sci. Technol. A 28, 314 (2010); 10.1116/1.3328053

Suppression of conductivity in Mn-doped $\mathrm{ZnO}$ thin films

J. Appl. Phys. 105, 013715 (2009); 10.1063/1.3063730

Effect of fluorine addition on transparent and conducting Al doped $\mathrm{ZnO}$ films J. Appl. Phys. 100, 063701 (2006); 10.1063/1.2347715

\section{AlP Re-register for Table of Content Alerts}




\title{
Differences in n-type doping efficiency between Al- and Ga-ZnO films
}

\author{
Mercedes Gabás, ${ }^{1, a)}$ Angel Landa-Cánovas, ${ }^{2}$ José Luis Costa-Krämer, ${ }^{3}$ \\ Fernando Agulló-Rueda, ${ }^{2}$ Agustín R. González-Elipe, ${ }^{4}$ Pilar Díaz-Carrasco, ${ }^{1}$ \\ Jorge Hernández-Moro, ${ }^{2}$ Israel Lorite, ${ }^{5,6}$ Pilar Herrero, ${ }^{2}$ Pedro Castillero, ${ }^{4}$ Angel Barranco, ${ }^{4}$ \\ and José Ramón Ramos-Barrado ${ }^{1}$ \\ ${ }^{1}$ Lab. de Materiales \& Superficies, Dpto. de Física Aplicada I, Universidad de Málaga, 29071 Málaga, Spain \\ ${ }^{2}$ Instituto de Ciencia de Materiales de Madrid, ICMM-CSIC, Cantoblanco, 28049 Madrid, Spain \\ ${ }^{3}$ Instituto de Microelectronica, IMM-CSIC, Isaac Newton 8 PTM, 28760 Madrid, Spain \\ ${ }^{4}$ Instituto de Ciencia de Materiales de Sevilla, ICMSE-CSIC, Américo Vespucio 49, Isla de la Cartuja, 41092 \\ Sevilla, Spain \\ ${ }^{5}$ Centro de Astrobiología, CSIC-INTA, Carretera de Ajalvir, Torrejon de Ardoz, 28850 Madrid, Spain \\ ${ }^{6}$ Institut für Experimentelle Physik II, Fakultät für Physik und Geowissenchaften, Universität Leipzig, \\ Linnéstraße 5, 04103 Leipzig, Germany
}

(Received 28 January 2013; accepted 11 April 2013; published online 30 April 2013)

\begin{abstract}
$\mathrm{A}$ careful and wide comparison between $\mathrm{Al}$ and $\mathrm{Ga}$ as substitutional dopants in the $\mathrm{ZnO}$ wurtzite structure is presented. Both cations behave as n-type dopants and their inclusion improves the optical and electrical properties of the $\mathrm{ZnO}$ matrix, making it more transparent in the visible range and rising up its electrical conductivity. However, the same dopant/Zn ratio leads to a very different doping efficiency when comparing $\mathrm{Al}$ and $\mathrm{Ga}$, being the $\mathrm{Ga}$ cation a more effective dopant of the $\mathrm{ZnO}$ film. The measured differences between $\mathrm{Al}$ - and Ga-doped films are explained with the hypothesis that different quantities of these dopant cations are able to enter substitutionally in the $\mathrm{ZnO}$ matrix. Ga cations seem to behave as perfect substitutional dopants, while Al cation might occupy either substitutional or interstitial sites. Moreover, the subsequent charge balance after doping appear to be related with the formation of different intrinsic defects that depends on the dopant cation. The knowledge of the doped- $\mathrm{ZnO}$ films microstructure is a crucial step to optimize the deposition of transparent conducting electrodes for solar cells, displays, and other photoelectronic devices. (C) 2013 AIP Publishing LLC. [http://dx.doi.org/10.1063/1.4803063]
\end{abstract}

\section{INTRODUCTION}

$\mathrm{ZnO}$ based materials have many potential applications in several optoelectronic and spintronic devices such as flat panel displays, light emitting diodes, solar cells, etc. Their extraordinary structural, chemical, electrical, and optical properties, together with the large variety of preparation methods suitable for the manufacturing of a high quality film make them one of the most versatile materials in current technology. ${ }^{1} \mathrm{~N}$-type doped $\mathrm{ZnO}$ is probably the most promising transparent conducting oxide (TCO) to be used as a transparent electrode in many different applications. ${ }^{2}$ In particular, the optimization of its role as current collector could be a fundamental step in the fabrication of efficient and competitive thin film solar cells. ${ }^{3}$

$\mathrm{ZnO}$ n-type doping is achieved by substitution of $\mathrm{Zn}^{2+}$ cations with group III elements ( $\mathrm{Al}, \mathrm{Ga}$, In). The efficiency of the dopant element is related with its electronegativity and differences between ionic radii. The best option, regarding the improvement in electrical and optical properties, seemed to be In, at an atomic concentration of $1 \%{ }^{4}$ However, economical and environmental arguments advice against this option, due to the natural scarcity of indium and its toxicity. Al- and Ga-doped $\mathrm{ZnOs}$ are currently the best candidates for use as indium-tin-oxide (ITO) substitutes in the thin film transparent electrode technology. ${ }^{5}$ Both of them meet the transparent

\footnotetext{
a) Author to whom correspondence should be addressed. Electronic mail: mgabas@uma.es.
}

conducting oxide requirements in terms of high transmittance in the visible region and large electrical conductivity values. One of the open questions when comparing these cations as dopants within the $\mathrm{ZnO}$ matrix is the limit of the effective substitutional doping for each case. Most of the works describing the properties of doped $\mathrm{ZnO}$ films simply quantify the dopant concentration before the preparation of the film, as a weight percentage in a solid target, or as a molar concentration in a liquid/solid solution. In many experimental reports, the quantity of dopant cations compared to $\mathrm{Zn}$ cations in the $\mathrm{ZnO}$ matrix remains unknown and so does the proportion of doping elements which are in substitutional positions. It is thus imperative to know the real concentration of substitutional cations in the wurtzite structure in every case, in order to do a proper comparison of the effectiveness of different dopants. Since measuring the carrier density is also not conclusive due to charge compensation effects, in our study, the dopant concentration has been measured directly in the sample and its value was chosen accordingly to the best performance results presented in other experimental reports. ${ }^{4,6,7}$

Magnetron sputtering has been one of the preferred methods to grow $\mathrm{ZnO}$ films because of its low cost, simplicity, and low operating temperature. The process parameters, such as doping concentration, deposition temperature and pressure can be easily modulated in order to get low resistivity TCO films. ${ }^{6,8}$ The preparation of high-quality single crystal $\mathrm{ZnO}$ films is also achieved using the appropriate substrate temperature-rf power combination. ${ }^{9}$ The use of relatively 
low temperatures during film preparation allows the implementation of a large variety of substrates and opens the possibility of using $\mathrm{ZnO}$ based materials as transparent electrodes in flexible electronics. ${ }^{10,11}$

In this work, we present the comparison among $\mathrm{ZnO}$, $\mathrm{Al}: \mathrm{ZnO}$, and $\mathrm{Ga}: \mathrm{ZnO}$ thin films prepared on $\mathrm{Si}(100)$ and silica substrates under identical deposition conditions, correlating the conductivity and changes in the optical properties with the microstructure variations induced by doping. For a better comparison, both doped films have been prepared with the same ratio [dopant]/[Zn]. A large number of characterization techniques have been used in order to fully understand the differences between our sputtered $\mathrm{Ga}$ and $\mathrm{Al}$ doped $\mathrm{ZnO}$ films.

\section{EXPERIMENTAL}

$\mathrm{ZnO}, \mathrm{Al}: \mathrm{ZnO}$, and $\mathrm{Ga}: \mathrm{ZnO}$ films were deposited on both polished Si (100) and amorphous silica substrates using a RF magnetron sputtering system. Three types of ceramic targets (AJA International, Inc.) were employed: pure $\mathrm{ZnO}$ (99.99\%), $\mathrm{ZnO}$ with a $\mathrm{Ga}_{2} \mathrm{O}_{3}$ content of 2 wt. \% (99.9\%), and pure $\mathrm{Al}_{2} \mathrm{O}_{3}$ (99.99\%). The diameter of the targets was $5 \mathrm{~cm}$, and the substrate-to-target distance was $3 \mathrm{~cm}$. The base pressure in the chamber was below $5 \times 10^{-4} \mathrm{~Pa}$, and the working sputtering pressure was maintained at $0.4 \mathrm{~Pa}$ with a high purity Ar gas regulated by a mass flow controller. The $\mathrm{RF}$ sputtering power was fixed at $150 \mathrm{~W}$ for the $\mathrm{ZnO}$ and $\mathrm{ZnO}: \mathrm{Ga}_{2} \mathrm{O}_{3}$ targets and at $45 \mathrm{~W}$ for the $\mathrm{Al}_{2} \mathrm{O}_{3}$ one. The substrate temperature was kept at $300^{\circ} \mathrm{C}$, and the deposition time was 20 min except for the films studied by Raman spectroscopy where longer deposition times were used in order to get thicker films. With these deposition parameters, the dopant concentration in the two doped films achieved a $2 \%$ dopant/Zn ratio value, quite constant along the whole film thicknesses as determined by X-ray energy dispersive analysis (XEDS).

$\mathrm{X}$-ray diffraction (XRD) patterns were obtained on a Philips X'Pert Pro MPD automated diffractometer, equipped with a $\mathrm{Ge}$ (111) primary monochromator (strictly monochromatic $\mathrm{CuK} \alpha_{1}$ radiation) and an $\mathrm{X}^{\prime}$ Celerator detector. The overall measurement time was $\sim 1 / 2 \mathrm{~h}$ per pattern. This recording time assures a good statistics over the $2 \theta$ range of $10^{\circ}-80^{\circ}$ with $0.017^{\circ}$ step size.

$\mathrm{X}$-ray photoelectron spectroscopy (XPS) spectra were obtained using a Physical Electronic model PHI 5700 X-ray photoelectron spectrometer with $\mathrm{Mg} \quad \mathrm{K} \alpha$ radiation $(1253.6 \mathrm{eV})$ as excitation source. Measurements were done on as-prepared samples deposited on silicon and amorphous silica substrates and after $30 \mathrm{~s}$ of $\mathrm{Ar}^{+}$sputtering. This was done to avoid the effect of contamination due to air exposure of the samples. The core level spectra were fitted using the XPS PEAK software package. ${ }^{12}$

Raman spectra were measured with a Renishaw Ramascope 2000 microspectrometer and an ion argon laser (emission wavelength $514.5 \mathrm{~nm}$ ). A $100 \times$ microscope objective was used to focus the laser on the sample and to collect the scattered light. Laser power on the sample was about $3 \mathrm{~mW}$. $\mathrm{ZnO}$ films with a thickness of several hundreds $\mathrm{nm}$ grown on silica were employed in order to reduce Raman scattering from the substrate. The latter was subtracted numerically as explained elsewhere. ${ }^{13}$

Cross-sectional samples were prepared for transmission electron microscopy (TEM) examination by dimple-grinding with Gatan 656 dimpler and ion-milling with a Fischione 1010 model until an electron transparent area was obtained in the center of the sample. Transmission electron microscopy studies were done in a JEOL 3010 F TEM microscope with a field-emission gun, $300 \mathrm{kV}$ acceleration bias and with about $0.17 \mathrm{~nm}$ structural size resolution.

Optical transmittance measurements were performed for the films grown on amorphous silica substrate, using a UVvisible spectrophotometer (Varian Cary 5000) within the wavelength range from 300 to $800 \mathrm{~nm}$.

Continuous wave photoluminescence (PL) measurements were carried out at room temperature in the front face configuration using a Horiba Jobin Yvon Fluorolog3 fluorimeter equipped with a $450 \mathrm{~W}$ Xe lamp and two monochromators. The excitation monochromator, located between the source and the sample, was used to select the wavelength of the pumping beam, which was set at 235, 240, and $280 \mathrm{~nm}$ for $\mathrm{ZnO}, \mathrm{Ga}: \mathrm{ZnO}$, and $\mathrm{Al}: \mathrm{ZnO}$, respectively. The light emitted by the sample was collected by a photomultiplier (PMT) detector through the emission monochromator. PL measurements were performed by scanning the emission wavelength between 325 and $700 \mathrm{~nm}$ with a $5 \mathrm{~nm}$ monochromator step. The system was equipped with filters in order to remove stray light effects, and the measured spectra were corrected from variations of the pumping intensity. All the films were measured in identical experimental conditions in order to be able to compare quantitatively their PL intensities. Excitation spectra were recorded by collecting the light at a wavelength of $393 \mathrm{~nm}$ for $\mathrm{ZnO}$ and $\mathrm{Ga}: \mathrm{ZnO}$, and $370 \mathrm{~nm}$ for $\mathrm{Al}: \mathrm{ZnO}$.

Electrical properties of the films were measured from 10 to $300 \mathrm{~K}$ in a closed cycle refrigerator system. The electrical contacts were made through a physical mask by an e-beam evaporator in the sequence Ti $(150 \AA), \operatorname{Al}(150 \AA), \operatorname{Pt}(150 \AA)$, $\mathrm{Au}(150 \AA)$. The contacts, about $0.5 \mathrm{~mm}$ in diameter, were placed at the film $\left(10 \times 10 \mathrm{~mm}^{2}\right)$ corners since the Hall effect system uses the four probe van der Pauw method, ${ }^{14}$ i.e., switching consecutively the adjacent current injection and voltage measurement pairs, to reduce as much as possible measurement artifacts. The magnetic field and electrical current direction are both switched in the measurement sequence at a given temperature, averaging out unwanted voltage sources. The ohmic character of the contacts was checked prior to the cooling down/warming up measurement cycle. Typical two probe resistances in a $10 \times 10 \mathrm{~mm}^{2}, 100 \mathrm{~nm}$ thick film were of the order of $\mathrm{k} \Omega$. A $0.1 \mathrm{~mA}$ current and a magnetic field of $2200 \mathrm{G}$ were used for the reported measurements. A mild annealing of $200^{\circ} \mathrm{C}$ for $20 \mathrm{~min}$ in a nitrogen atmosphere was used to improve the contact resistance. This treatment only changed slightly (less than $2 \%$ ) the reported transport characteristics for the $\mathrm{Al}$ and $\mathrm{Ga}$ doped $\mathrm{ZnO}$ films, while for the pure $\mathrm{ZnO}$ had a more drastic effect, $\sim 50 \%$ decreasing its resistivity and increasing its carrier concentration, most probably due to a charge compensation effect. This is a consequence of the complex chemical defect chemistry of $\mathrm{ZnO}$, and their high mobilities at room temperature. ${ }^{15}$ 


\section{RESULTS}

\section{A. X-ray diffraction}

The structural characterization of the sputtered films was first accomplished using x-ray diffraction. Data were obtained from samples deposited onto $\mathrm{Si}$ substrates during $20 \mathrm{~min}$. The Si 100 substrate peak is used to calibrate the $2 \theta$ axis scale. The XRD patterns are very similar for all samples, showing only the wurtzite $\mathrm{ZnO} 002$ reflection in the $10^{\circ}-80^{\circ}$ $2 \theta$ range. This confirms that the films crystallize in the hexagonal wurtzite structure and are highly oriented with their crystallographic c-axis perpendicular to the substrate. This growth habit has been observed repeatedly for undoped $\mathrm{ZnO}$ and $\mathrm{Al}-$, Ga-doped $\mathrm{ZnO}$ films, irrespective of the preparation technique and substrate type. ${ }^{16,17}$ The position of the peak shifts slightly to larger angles with Ga doping (Figure 1), probably due to the smaller radius of $\mathrm{Ga}^{3+}$ ion compared to that of the $\mathrm{Zn}^{2+}$ ion, which should promote a small decrease of the cation-oxygen bond length along the c axis $(1.92 \AA$ for $\mathrm{Ga}-\mathrm{O}$ and $1.97 \AA$ for $\mathrm{Zn}-\mathrm{O}) .{ }^{18-20}$ On the contrary, the $\mathrm{Al}$ doped film peak appears $0.05^{\circ}$ shifted to smaller angles respect to the undoped film (Figure 1). This behaviour was quite unexpected since the $\mathrm{Al}^{3+}$ ion is even smaller than that of $\mathrm{Ga}^{3+}$. Other authors have also found this shift in Al-doped $\mathrm{ZnO}$ films and attributed it to the accumulation of residual stress in the plane of the films. ${ }^{17}$

In our films, there was also a very small increase with doping of the peak full width at half maximum (FWHM), with values of $0.20^{\circ}$ for $\mathrm{ZnO}$ to $0.22^{\circ}$ for $\mathrm{Ga}: \mathrm{ZnO}$ and $0.23^{\circ}$ for $\mathrm{Al}: \mathrm{ZnO}$. These higher FWHM values would be consistent with some a small decrease in the particle size along the growth direction.

\section{B. X-ray photoelectron spectroscopy}

XPS results obtained for films deposited onto a Si substrate for a deposition time of $20 \mathrm{~min}$ are shown herein. The spectra have not been corrected in energy. In a previous work, ${ }^{13}$ we established the independence of the XPS results

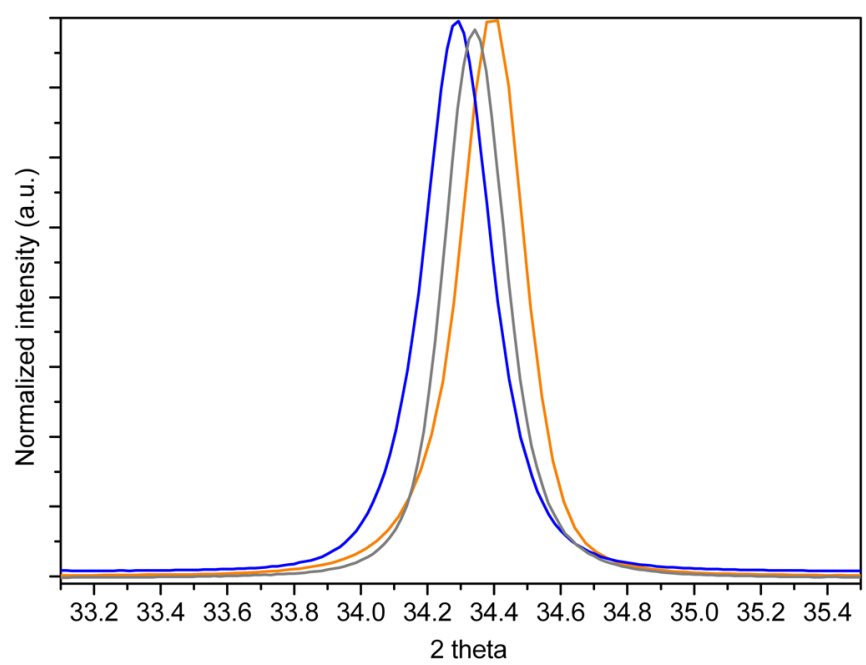

FIG. 1. X-ray diffractograms corresponding to $\mathrm{ZnO}$ (grey), Ga:ZnO (orange), and $\mathrm{Al}: \mathrm{ZnO}$ (blue) films showing the 002 reflection. on the film thickness and on the film substrate type. The XPS survey spectra looked very similar for the three materials, independently of doping. All the films presented a weak C 1s core level signal due to surface contaminants captured from air. This contamination could be easily removed after $30 \mathrm{~s}$ of $\mathrm{Ar}^{+}$sputtering.

$\mathrm{Zn} 2 \mathrm{p}$ core levels were similar in the three cases, and all the films exhibit single peaks centered at $1022.42 \pm 0.05 \mathrm{eV}$, with a $F W H M=1.93 \pm 0.02 \mathrm{eV}$ (not shown here). This means that no extra phases involving $\mathrm{Zn}$ are formed during film growth because of doping. Ga $2 \mathrm{p}_{3 / 2}$ as well as $\mathrm{Ga} 3 \mathrm{~s}$ core levels, and Ga LMM Auger peak, are visible as weak signals in the Ga doped film spectrum. A detailed analysis of these spectra was presented in Ref. 13. By contrast, no signal from any $\mathrm{Al}$ core level could be detected in the spectra from the $\mathrm{Al}$ doped film due to the small $\mathrm{Al} 2 \mathrm{p}$ core level crosssection at the incident photon energy used.

The effect of this dopant on the $\mathrm{ZnO}$ electronic structure could only be detected in an indirect way. After $30 \mathrm{~s}$ of mild $\mathrm{Ar}^{+}$sputtering, O1s core level spectra, corresponding to undoped $\mathrm{ZnO}$ and $\mathrm{Ga}$ and $\mathrm{Al}$ doped films, depicted some differences (see Figure 2). The peaks are clearly asymmetric, but the peak shapes presented significant differences for doped and undoped films. The deconvolution of the signals yields three different contributions, which are assigned along with the following arguments. The one centered at the lowest binding energy corresponds to the oxygen ions in the $\mathrm{ZnO}$ bulk wurtzite structure. The next one has its origin in the contaminants at the film surface for the undoped one, but its intensity is enhanced in the doped films. According to nucleus screening arguments, for the Ga doped films, it was already established that the contribution of oxygen ions close to dopant cations appears in the same binding energy range than the oxygen linked to contaminants. ${ }^{13}$ For the $\mathrm{Al}$ doped film, the lower electronegativity of $\mathrm{Al}$ (1.65) relative to $\mathrm{Ga}$ (1.81) would favor a certain displacement towards the oxygen anions of the electronic cloud of the cation-oxygen bond. As an effect that would agree with the spectrum in Figure 2, the peak corresponding to these oxygens appearing

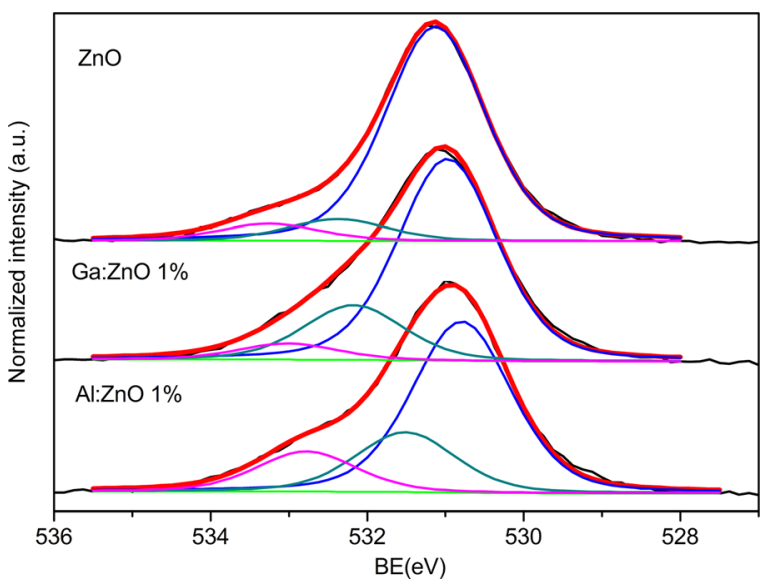

FIG. 2. O1s core level fits corresponding to $\mathrm{ZnO}$ (top), Ga: $\mathrm{ZnO}$ (middle), and $\mathrm{Al}: \mathrm{ZnO}$ (bottom) films. Peaks are deconvoluted into three components, from right to left: $\mathrm{O}$ linked to $\mathrm{Zn}$ cations, $\mathrm{O}$ linked to $\mathrm{C}+\mathrm{O}$ linked to dopant cations (for the $\mathrm{Ga}$ : and $\mathrm{Al}: \mathrm{ZnO}$ films), and $\mathrm{O}^{2-}, \mathrm{O}^{-}$, and $\mathrm{O}_{2}^{-}$at the film surface and grain boundaries. 
at lower binding energies than in the Ga doped film. The Al inclusion in the wurtzite structure would affect the film surface chemistry in a more significant way than the Ga inclusion. The third contribution to the $\mathrm{O} 1 \mathrm{~s}$ signal, at the highest binding energy, could have its origin in chemisorbed oxygen species like $\mathrm{O}^{2-}, \mathrm{O}^{-}$, and $\mathrm{O}_{2}^{-}$placed at the topmost layers of the film surface and at the grain boundaries. ${ }^{21,22}$ This contribution is more intense in the $\mathrm{Al}$ doped film, being the contributions in undoped and Ga doped film of similar intensity. A possible explanation is that the wurtzite structure distortion induced by doping is different for $\mathrm{Al}$ than for $\mathrm{Ga}$, which may favour the formation of different kind of intrinsic crystalline defects.

\section{Raman spectroscopy}

To complete the structural characterization of our films, we have also studied the vibrational properties. Raman spectra of the samples were obtained to see the differences. The results are summarized in Fig. 3 for the undoped and doped films. The spectra for the undoped and Ga-doped $\mathrm{ZnO}$ have been published before, ${ }^{13}$ but are reproduced here to compare with Al-doped samples.

The undoped film shows peaks at 98 and $439 \mathrm{~cm}^{-1}$, which correspond, respectively, to the $E_{2}$ (low) and $E_{2}$ (high) phonons of the $\mathrm{ZnO}$ wurtzite structure. ${ }^{1}$ No TO modes are observed, indicating that the backscattered light is collected along the $\mathrm{c}$ axis and confirming that the $\mathrm{ZnO}$ film grows along the (001) direction.

For the $\mathrm{Ga}$ and $\mathrm{Al}$ doped samples (Figure 3), the $E_{2}$ modes have the same frequency value as for the undoped sample and very similar to the values reported for bulk $\mathrm{ZnO},{ }^{1}$ indicating that stress effects are not important, ${ }^{22}$ with or without doping, in the studied films. The FWHM of $E_{2}$ (high) is about $6 \mathrm{~cm}^{-1}$ for all studied films. Since this parameter is very sensitive to crystal quality (being about $0.4 \mathrm{~cm}^{-1}$ for a good quality bulk crystal ${ }^{23}$ ), it indicates that the

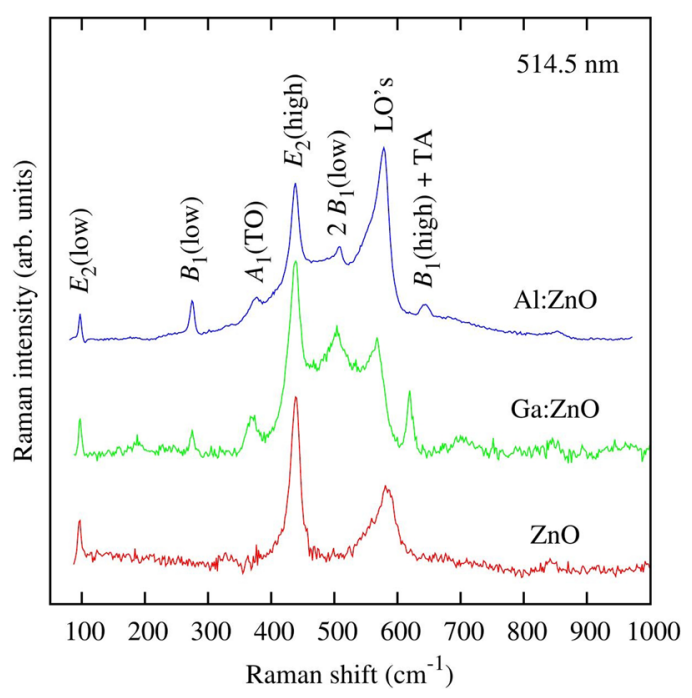

FIG. 3. Room temperature Raman spectra of undoped and doped $\mathrm{ZnO}$ films grown on silica. The background has been removed, and the spectra have been vertically offset for clarity. crystallinity of the samples does not change appreciably with Ga or Al doping.

Doping introduces new and well defined bands that have been attributed in the literature either to local vibrations of the impurity ions or to defect-induced forbidden modes of the original $\mathrm{ZnO}$ lattice. ${ }^{24}$ Following these authors, the new bands are assigned for $\mathrm{Ga}: \mathrm{ZnO}(\mathrm{Al}: \mathrm{ZnO})$ at 275 (275), 504 (508), and 620 (644) $\mathrm{cm}^{-1}$, respectively, to $B_{1}$ (low), 2 $B_{1}$ (low), and $B_{1}$ (high) + TA. The peak at $371(375) \mathrm{cm}^{-1}$ for the $\mathrm{Ga}(\mathrm{Al})$ doped film has been assigned to the $A_{1}$ (TO) mode. It could appear because of a slight misalignment of the $\mathrm{c}$ axis which has not been observed by XRD nor TEM. The peak at 567 and $576 \mathrm{~cm}^{-1}$ obtained for the $\mathrm{Ga}$ and $\mathrm{Al}$ doped films, respectively, is underneath the peak found for the undoped film $\left(585 \mathrm{~cm}^{-1}\right)$. In the undoped film, it has been assigned to the overlapping of the $E_{1}(\mathrm{LO})$ and $A_{1}(\mathrm{LO})$ modes. In the doped films, different proportions of the contributions due to $A_{1}(\mathrm{LO})$ and the forbidden $B_{1}$ (high) peaks could be responsible of the observed energy shifts. ${ }^{25}$ However, additional theoretical calculations, which are beyond the scope of this work, are needed to fully understand the vibrational behavior of doped $\mathrm{ZnO}$.

\section{Transmission electron microscopy}

High resolution transmission electron microscopy (HRTEM) images of the films prepared during $20 \mathrm{~min}$ on $\mathrm{Si}$ substrates are presented in Figure 4. X-ray energy dispersive analysis measurements on the TEM prepared cross sections give a dopant cation/ $\mathrm{Zn}$ ratio of around $2 \%$, throughout the whole doped films. Similar analysis in a scanning electron microscope set up were performed on a thick Ga doped film, give the same result for the $[\mathrm{Ga}] /[\mathrm{Zn}]$ ratio. Figures 4(a)-4(c) show low magnification images of the films, while Figures 4(d)-4(f) present a higher magnification view of the interface area. In the low magnification images, the whole thickness of the $\mathrm{ZnO}$ film can be assessed, being of 70-80 nm for $\mathrm{ZnO}$ and $\mathrm{Ga}: \mathrm{ZnO}$ films and slightly thicker $(110-120 \mathrm{~nm})$ in the case of $\mathrm{Al}: \mathrm{ZnO}$. Again Al dopant promotes a more pronounced change than $\mathrm{Ga}$ in $\mathrm{ZnO}$ sputtered films.

Another difference that can be distinguished from the low magnification images is the roughness of the surface. The pure $\mathrm{ZnO}$ surface presents a remarkable surface roughness with almost $10 \mathrm{~nm}$ between peaks and valleys. The individual $\mathrm{ZnO}$ grains seem to be very crystalline and with an "obelisk" prismatic shape. Al:ZnO films show an intermediate roughness. However, the $\mathrm{Ga}: \mathrm{ZnO}$ films show very flat surfaces, likely indicating a different surface termination of the grains: (1-102) for the undoped and $\mathrm{Al}$ doped films vs. (0001) for the Ga doped one.

HRTEM images of Figures 4(d)-4(f) show the formation of a thin amorphous layer between the $\mathrm{ZnO}$ and the silicon films. The thickness of this layer increases from pure $\mathrm{ZnO}(2 \mathrm{~nm})$ to $\mathrm{Al}: \mathrm{ZnO}(4 \mathrm{~nm})$, being $\mathrm{Ga}: \mathrm{ZnO}$ intermediate $(3 \mathrm{~nm})$. The soft contrast gradation from dark grey $\mathrm{ZnO}$ to light grey suggests a gradual transition $\mathrm{Zn}_{1-\mathrm{x}} \mathrm{Si}_{\mathrm{x}} \mathrm{O}_{2} / \mathrm{SiO}_{2}$ in the interface that depends on doping. Besides, a dopant enrichment is quite plausible at the interface between doped 

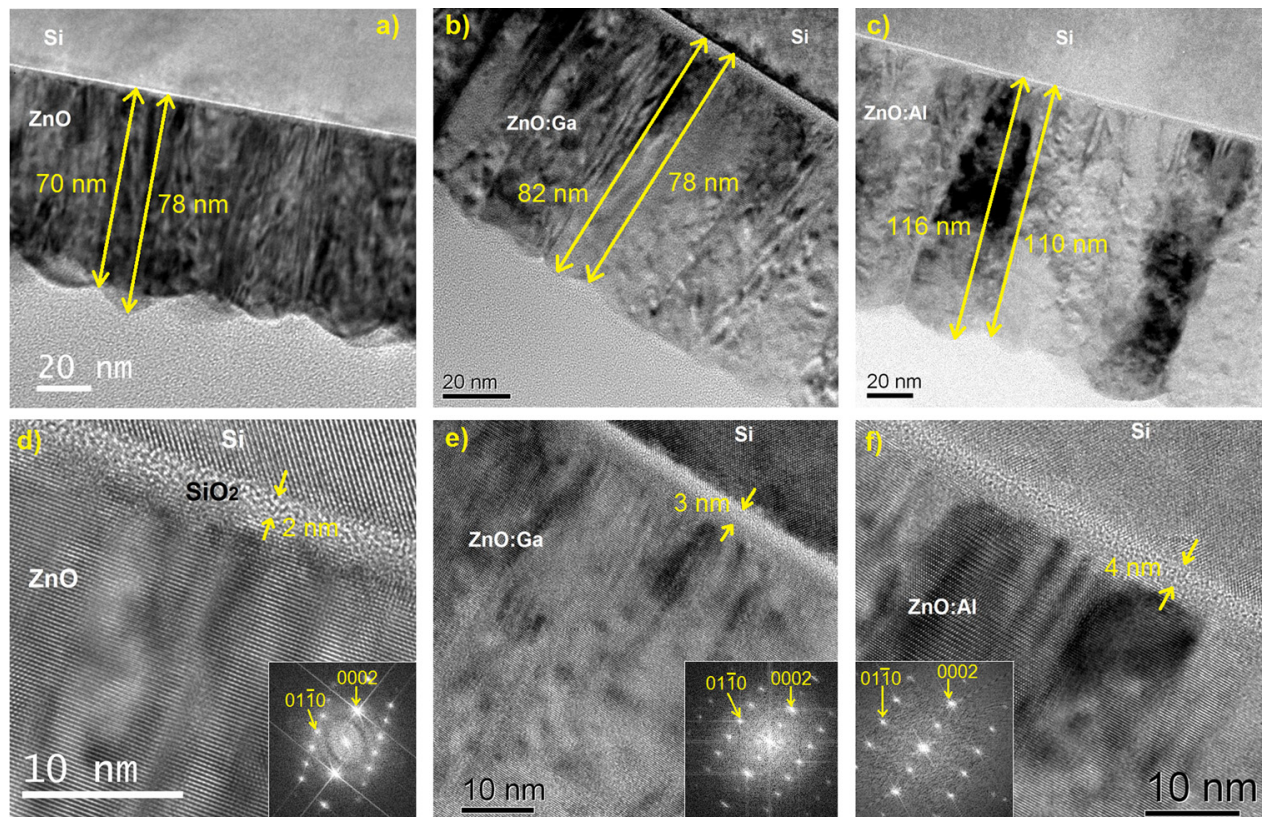

FIG. 4. HRTEM images of $\mathrm{ZnO}$ (a) and (d), Ga:ZnO (b) and (e), and $\mathrm{Al}: \mathrm{ZnO}$ (c) and (f) films on polished $\mathrm{Si}(100)$. films and substrate, as it has been already observed in $\mathrm{Al}$ and Ga doped $\mathrm{ZnO}$ films. ${ }^{26,27}$

On the other hand, no difference is observed in the continuity of the (0002) $\mathrm{ZnO}$ lattice planes, which run parallel to the $\mathrm{ZnO} / \mathrm{Si}$ interface through the different $\mathrm{ZnO}$ grains, independently of doping. In all three cases, the planes show a wavy trajectory due to a large amount of edge dislocations present at the grain boundaries. Our experimental results discard the formation of spurious phases and extended defects probing the good quality of the sputtered films.

\section{E. Optical transmittance}

The optical characterization of the films has been accomplished through optical transmittance and photoluminescence experiments. Optical transmittance measurements were done within the wavelength range $300-800 \mathrm{~nm}$, thus covering the full visible spectrum. The spectra from films deposited onto silica substrates exhibit a sharp ultraviolet absorption edge independently of doping and a transmittance of less than $80 \%$ for the $\mathrm{ZnO}$ and about $85 \%$ for the $\mathrm{Ga}: \mathrm{ZnO}$ and $\mathrm{Al}: \mathrm{ZnO}$ films in the visible region. Hence, doping reinforces the transparency of the films, an important result considering their potential applications as TCOs.

From these measurements, the band-gap values can be directly calculated. The optical bandgap energy Eg was determined using the equation $(\alpha \mathrm{h} \nu)^{2}=\mathrm{C}(\mathrm{h} \nu-\mathrm{Eg})$, where $\mathrm{C}$ is a constant that depends on the electron-hole mobility, and $\mathrm{h} \nu$ is the photon energy. The bandgap (Eg) was estimated by extrapolating the linear portion to the energy axis in the $(\alpha \mathrm{h} \nu)^{2}$ vs. h $\nu$ graph (see Figure 5).

The obtained results were $3.21 \mathrm{eV}$ for the undoped film and 3.25 and $3.63 \mathrm{eV}$, when $\mathrm{ZnO}$ is doped with $\mathrm{Al}$ and $\mathrm{Ga}$ (1 at. \%), respectively. The blue shift in the band gap of the n-type doped $\mathrm{ZnO}$ films has been widely observed, and it has been attributed to the Burstein-Moss shift due to the increase in carrier concentration, ${ }^{4}$ although some authors mention the presence of enhanced stress in Al-doped films as a possible origin of this shift. ${ }^{28}$ The more pronounced shift for the Ga-doped film would make it more suitable for TCO applications.

\section{F. Photoluminescence}

The fluorescence characterization of the films, reported in Figure 6, show the excitation and photoluminescence spectra plotted in a normalized scale after recording as described in Sec. II. The excitation spectra reported in Figure 6 (left) show that the wavelength of the emission maxima is ordered according to $\mathrm{ZnO}>\mathrm{Ga}: \mathrm{ZnO}>>\mathrm{Al}: \mathrm{ZnO}$. The last film, Al:ZnO, also differs in the width of the spectrum, much larger than in the other two cases.

Significant differences can be also found when looking to the luminescent spectra reported in the same figure (right). Although a straightforward quantification of luminescence spectra is not possible, the considerable differences in intensity found between the three thin films permits to carry out a qualitative assessment based on this parameter. Thus, a first remarkable difference when comparing these spectra is the

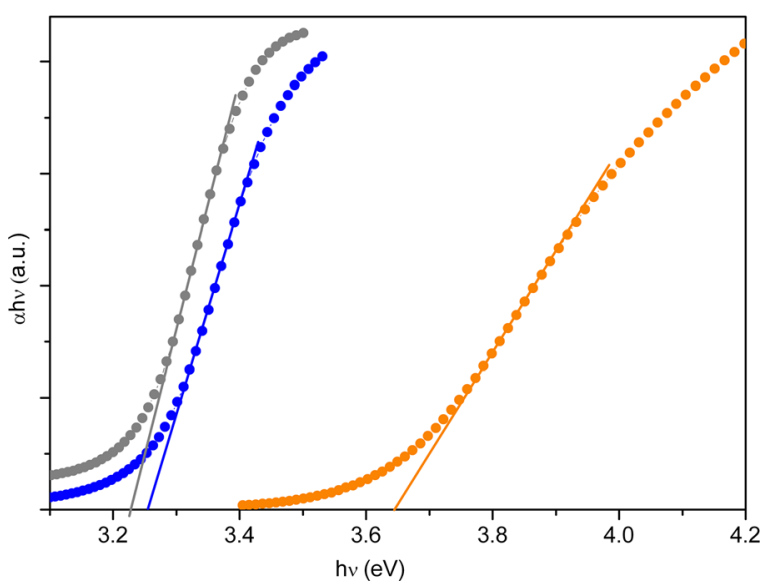

FIG. 5. Estimation of band-gaps for the films $\mathrm{ZnO}$ (grey), Ga: $\mathrm{ZnO}$ (orange), and $\mathrm{Al}: \mathrm{ZnO}$ (blue). 


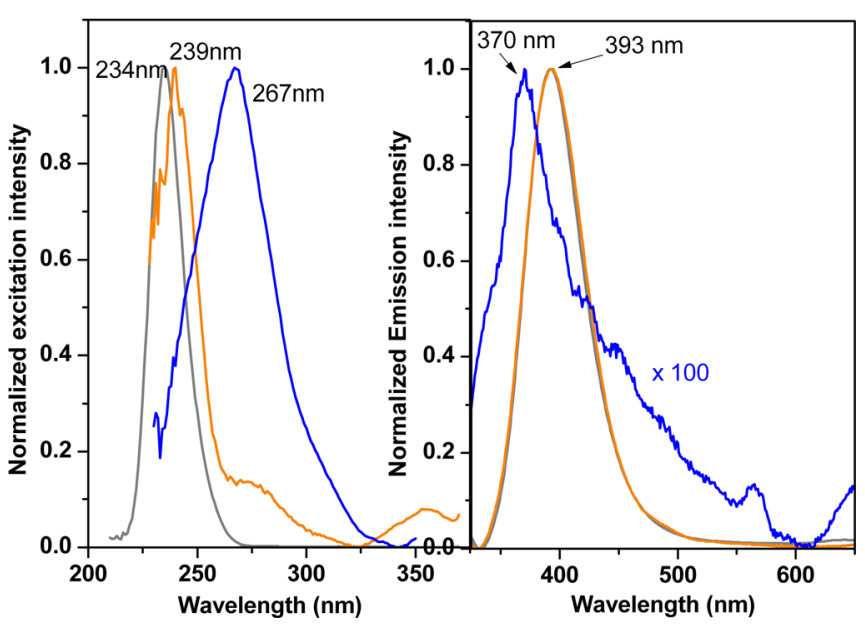

FIG. 6. Excitation (left) and normalized photoluminescence (right) spectra recorded at room temperature for the investigated films: $\mathrm{ZnO}$ (grey), $\mathrm{Ga}: \mathrm{ZnO}$ (orange), and $\mathrm{Al}: \mathrm{ZnO}$ (blue). Note the multiplication factor used to bring all the spectra to a common scale.

much higher intensity emission found for pure $\mathrm{ZnO}$ in comparison with the doped thin films. When comparing the two doped films, it is apparent the very small emission found for the $\mathrm{Al}: \mathrm{ZnO}$ film. In addition, another significant difference is the position of the PL maximum in $\mathrm{Al}: \mathrm{ZnO}$ (i.e., $370 \mathrm{~nm}$ ), in comparison with $\mathrm{ZnO}$ and $\mathrm{Ga}: \mathrm{ZnO}$ (i.e., $393 \mathrm{~nm}$ ).

The UV PL band of $\mathrm{ZnO}$ is usually attributed to radiative excitonic recombinations, ${ }^{29}$ and at room temperature, it results from the convolution of a pure exciton component appearing at higher energy and phonon replicas at lower energy that merge together into an unresolved peak due to thermal damping. The PL band of a perfect crystal is governed by the exciton peak, whereas those of a defective and polycrystalline material usually present stronger contributions from the phonon replicas. ${ }^{30}$ Thus, differences in the PL spectra shapes presented in Figure 6 (right) would reflect the different role that phonon contribution plays in the fluorescence process in the Al-doped film, compared to undoped and Ga-doped ones. The rather broad shape of the PL exciton curve extending into the visible region in $\mathrm{ZnO}$ and $\mathrm{Ga}: \mathrm{ZnO}$ sustains a substantial contribution of phonon replicas in the spectra of these two thin films. PL spectra are very similar, which would be an indication of the similarities between the $\mathrm{ZnO}$ and the $\mathrm{Ga}: \mathrm{ZnO}$ lattices. In $\mathrm{Al}: \mathrm{ZnO}$ thin film, even if very small, the phonon replicas contribution to PL spectrum is very different from the other films, so that its convolution with the exciton peak would shift the observed PL maximum towards higher energies.

In previous studies with $\mathrm{Al}: \mathrm{ZnO}$ thin films prepared by sol-gel and an aluminum concentration ranging between $2 \%$ and $6 \%$, it was found that the intensity of the PL spectra increases with $\mathrm{Al}$ doping. ${ }^{31}$ The almost negligible intensity of PL found in our case suggests that the $\mathrm{Al}: \mathrm{ZnO}$ thin film has a high concentration of recombination centers producing a drastic decrease in the formation of long life excitons. Comparing $\mathrm{ZnO}$ with $\mathrm{Ga}: \mathrm{ZnO}$, the former has a more intense PL peak, while none of them present a significant PL emission in the visible. In other $\mathrm{ZnO}$ systems, visible PL bands are attributed to radiative recombinations involving defect states located in the band gap. ${ }^{29,31}$ The good crystallinity of these thin films supports the absence of a high concentration of such type of electronic states in the undoped and $\mathrm{Ga}$ doped films.

\section{G. Hall effect measurements}

Finally the improvements on the suitability of doped $\mathrm{ZnO}$ films as transparent conductors have been explored through their electrical characterization. The transport characteristics of the $\mathrm{ZnO}$ films have been determined through Hall effect measurements. The resistivity behavior as a function of temperature is shown in Figure 7. $\mathrm{ZnO}$ and $\mathrm{Al}: \mathrm{ZnO}$ films have the typical semiconductor behavior, with decreasing values as temperature increases. On doping with aluminum, the resistivity decreases one order of magnitude as a consequence of the increase in charge carrier number. Meanwhile, on doping with gallium, quite a different temperature tendency is observed. The resistivity behavior turns metallic in the whole measured temperature range and diminishes to values on the order of $9 \times 10^{-4} \Omega \mathrm{cm}$. Previous results in literature report a metal-semiconductor transition at low temperatures in $\mathrm{Ga}$ doped $\mathrm{ZnO}$ films. ${ }^{32,33}$ However, according to these experimental results, in our Ga-doped film, this transition should occur below $\sim 10 \mathrm{~K}$, which is a quite unexpected result since it means a really good efficiency of Ga cation as dopant in the $\mathrm{ZnO}$ matrix.

The carrier densities and mobilities for doped films are shown on Figure 8. One order of magnitude separate carrier densities corresponding to $\mathrm{Al}$ doped film $\left(\sim 3 \times 10^{19} \mathrm{~cm}^{-3}\right)$ and Ga doped film $\left(\sim 5 \times 10^{20} \mathrm{~cm}^{-3}\right)$. They are both quite well defined and constant with temperature. Besides the larger quantity of charge carriers in the Ga: $\mathrm{ZnO}$ film, its mobility has also improved when compared to the $\mathrm{Al}: \mathrm{ZnO}$ film. Different tendencies with temperature are observed, being the Ga doped film mobility slightly decreasing with temperature while the $\mathrm{Al}$ doped film one increases.

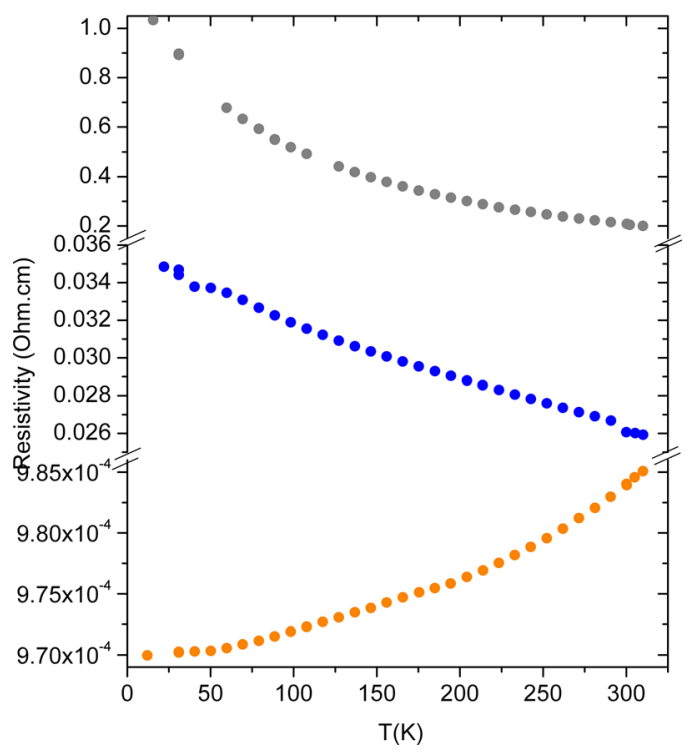

FIG. 7. Resistivity behavior of the $\mathrm{ZnO}$ (top, grey circles), $\mathrm{Al}: \mathrm{ZnO}$ (middle, blue circles), and $\mathrm{Ga}: \mathrm{ZnO}$ (bottom, orange circles) films as a function of temperature. 


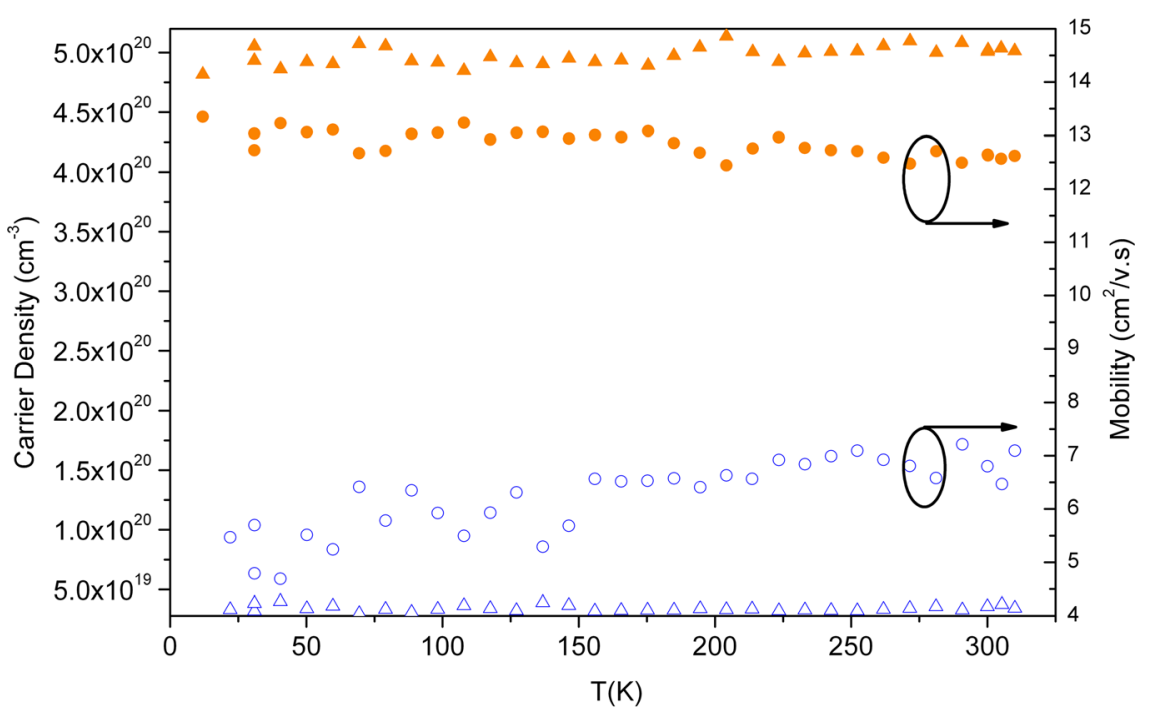

FIG. 8. Carrier densities (triangles) and mobilities (circles) as a function of temperature for the doped films. Full symbols (orange) correspond to $\mathrm{Ga}: \mathrm{ZnO}$ film, and open symbols (blue) correspond to $\mathrm{Al}: \mathrm{ZnO}$ film.
It is worth noticing here that both doped films have the same dopant/Zn ratio and in spite of that fact, we have measured noticeable differences between the electrical properties of $\mathrm{Al}: \mathrm{ZnO}$ and $\mathrm{Ga}: \mathrm{ZnO}$ films. From our results, it is evident that not all the extra-electrons introduced by $\mathrm{Al}$ cations become charge carriers in the $\mathrm{ZnO}$ matrix. On the contrary, the higher carrier density in the Ga-doped film is another proof of the efficiency of Ga cations as substitutional dopants, while Al cations seem to be placed in both, interstitial and substitutional sites, within $\mathrm{ZnO}$ lattice. This comes out of a simple calculation that shows that about $1 \% \mathrm{Al}$ or $\mathrm{Ga}$ substitutional doping of $\mathrm{ZnO}$ would produce carrier concentrations of the order of the measured ones for the Ga doped film $\sim 5 \times 10^{20} \mathrm{~cm}^{-3}$.

\section{DISCUSSION}

When comparing the behavior of undoped $\mathrm{ZnO}$, Gadoped and Al-doped films, there are several uncommon experimental findings that deserve attention: the abnormal shift in XRD Al:ZnO film peak, the photoluminescence results with a similar behavior for the undoped and $\mathrm{Ga}$ doped film vs. $\mathrm{Al}: \mathrm{ZnO}$ film, and the reduced electrical doping efficiency of $\mathrm{Al}: \mathrm{ZnO}$ film when compared with that of Ga: $\mathrm{ZnO}$.

The last result is probably related with the Ga cations preference to substitute $\mathrm{Zn}$ ones in their original positions within the crystalline lattice, at least at our concentration level, while the Al cations would occupy both available sites, substitutional and interstitial. The small $\mathrm{Al}$ ionic radius could be the origin of this ability. In agreement with our experimental results, the inclusion of $\mathrm{Al}$ cations in interstitials sites would have an immediate growing effect on the unit cell size. On the contrary, if we assume that Ga cations would only be placed in substitutional sites, the different ionic radii: $0.60 \AA\left(\mathrm{Zn}^{2+}(\mathrm{IV})\right)$ vs. $0.47 \AA\left(\mathrm{Ga}^{3+}(\mathrm{IV})\right){ }^{34}$ (IV indicates that the ionic radii are given for coordination number IV), would induce a small reduction of the unit cell parameters, as observed in the X-ray diffractogram. Moreover, due to their different cationic radii, $\mathrm{Al}$ and $\mathrm{Ga}$ would not produce the same distortion when included in a substitutional site in the $\mathrm{ZnO}$ matrix. Our experimental results suggest that dopant inclusion would affect the concentration of the different intrinsic defects in the $\mathrm{ZnO}$ structure, and this alteration would depend on the dopant cation. Cationic substitution of $\mathrm{Zn}^{2+}$ by a cation $\mathrm{M}^{3+}$ must have important consequences on the atomic lattice of the $\mathrm{ZnO}$ matrix. From a structural point of view, two different mechanisms can occur to accommodate the substitution of the $\mathrm{Zn}^{2+}$ by a trivalent cation. The first one would consist on the creation of cationic vacancies according to the following reaction:

$$
3 \mathrm{Zn}^{2+} \rightarrow 2 \mathrm{M}^{3+}+\mathrm{V}_{\text {cat }}
$$

According to this reaction, in order to maintain the charge balance, 2 cations $\mathrm{M}^{3+}$ must substitute 3 cations $\mathrm{Zn}^{2+}$, and therefore, cation vacancies should be created in the cationic sublattice.

Another possible mechanism might proceed according to the following reaction:

$$
\mathrm{Zn}^{2+} \rightarrow \mathrm{M}^{3+}+1 / 2 \mathrm{O}^{2-}{ }_{\text {int }}
$$

i.e., the charge balance is maintained by introducing $\mathrm{O}^{2-}$ interstitials in the anionic sublattice. Since the most common defect found in pure $\mathrm{ZnO}$ consists of oxygen vacancies, ${ }^{35}$ it is quite reasonable to assume that the interstitial oxygens generated by the mechanism of reaction (2) would occupy the original oxygen vacancies in $\mathrm{ZnO}$. Therefore, mechanism (2) would not introduce an extra quantity of intrinsic defects in the $\mathrm{ZnO}$ structural lattice and the induced variations in the mean unit cell size would obey to the ionic radii change. Our experimental results point to the fact that $\mathrm{Ga}$ doping in our sputtered films is ruled by mechanism (2). The unit cell diminution and the evidences of a very small lattice distortion reflected in PL spectra would support this hypothesis.

On the other hand, although substitution of $\mathrm{Zn}^{2+}$ by $\mathrm{Al}^{3+}$ with an ionic radius $\mathrm{Al}^{3+}(\mathrm{IV})$ of $0.39 \AA$ should further decrease the unit cell parameters, the apparent increase of the $c$ parameter observed in the X-ray diffractogram could be explained with the presence of $\mathrm{Al}$ cations in interstitial sites, and it would be enhanced by the creation of cation vacancies according to mechanism (1). The presence of these 
vacancies in the crystal would cause a relaxation of the structure in the immediate environment of the vacancy, i.e., the atoms surrounding the vacancy will relax outwards. This relaxation could compensate the introduction of smaller atoms such as $\mathrm{Al}^{3+}$ in the $\mathrm{ZnO}$ lattice. This effect has been already observed in some other lattices. For example in the rutile phase $\mathrm{SbVO}_{4}$, when oxidizing $\mathrm{V}^{3+}$ to $\mathrm{V}^{4+}$, the introduction of cation vacancies compensates the substitution of $\mathrm{V}^{3+}$ by a smaller cation $\mathrm{V}^{4+} \cdot{ }^{36,37}$ In the present case of $\mathrm{Al}^{3+}$ doping, the addition of cation vacancies in $\mathrm{ZnO}$ would increase the unit cell size in $\mathrm{Al}: \mathrm{ZnO}$ film.

These structural modifications and the concomitant variation in the intrinsic defect type distribution can explain some of the measured property differences between $\mathrm{Al}: \mathrm{ZnO}$ and $\mathrm{Ga}: \mathrm{ZnO}$ films. Photoluminescence results point to a very similar behavior between undoped and Ga-doped films, while Al-doped film spectrum shows a shift in the photoluminescence band maximum and a different shape. These experimental findings could be associated to the presence of charge compensating defects in the $\mathrm{ZnO}$ lattice when $\mathrm{Al}$ cations are introduced in both substitutional and interstitial sites.

Though the extrapolation of experimental results got from some other samples prepared by different preparation techniques is quite difficult and not obvious, we would like to mention here two previous works that have explored the position of $\mathrm{Al}$ and $\mathrm{Ga}$ cations in the $\mathrm{ZnO}$ lattice using different characterization techniques. In the work of Brehm et al. ${ }^{38}$ the local structure of $\mathrm{Ga}$ and $\mathrm{Al}$ doped $\mathrm{ZnO}$ powders is investigated using XRD and extended X-ray absorption fine structure (EXAFS). Their results are not conclusive on the location of Ga cations and its presence as substitutional as well as interstitials defects is compatible with their experimental findings. However, it should be noted that their samples were more heavily doped $\mathrm{ZnO}$ powders than our $1 \%$ at. Ga: $\mathrm{ZnO}$ films. They do find a six-fold coordination in interstitial sites as the more probable configuration for a $2 \%$ at. (nominally) doped $\mathrm{Al}: \mathrm{ZnO}$ powder. The nuclear magnetic resonance (NMR) results presented by Noriega et al., ${ }^{39}$ also point to the incorporation of most of the $\mathrm{Al}$ cations in a six-fold coordination neighborhood, even at low dopant concentration.

\section{CONCLUSIONS}

A careful and complete comparison between undoped $\mathrm{ZnO}$ films and $\mathrm{ZnO}$ films doped with $\mathrm{Al}$ or $\mathrm{Ga}$ cations (1\% at.) has been carried out. Both dopants improve the film optical and electrical properties compared to undoped $\mathrm{ZnO}$, showing the $\mathrm{Al}: \mathrm{ZnO}$ and $\mathrm{Ga}: \mathrm{ZnO}$ possibilities as alternative TCOs for several optoelectronic devices. The films' electrical properties reveal that $\mathrm{Ga}$ is much more effective as n-type dopant than $\mathrm{Al}$ at our dopant concentration level. This in spite that the number of dopant ions introduced is similar in both cases as indicated by the equivalent dopant/Zn ratio. Our experimental findings evidence significant differences between the Al- and Ga-doped films that could be explained if the $\mathrm{Al}$ inclusion in the $\mathrm{ZnO}$ wurtzite structure places these cations in both substitutional and interstitial sites, while $\mathrm{Ga}$ cations only would occupy substitutional sites. The Al cations placed at interstitial sites are ruled out as charge carrier donors, since the carrier concentration of $\mathrm{Al}: \mathrm{ZnO}$ is basically 1/10 of that of Ga:ZnO. This establishes the different Al efficiencies as substitutional dopant with respect to Ga. The substitution of the $\mathrm{Zn}^{2+}$ by a trivalent cation would follow two different charge compensation mechanisms depending on the dopant. The creation of a different type of intrinsic defect in each case would be the immediate consequence: oxygen interstitials when $\mathrm{Ga}$ doping, and cation vacancies if $\mathrm{Al}$ is used as dopant. In this last case, there would be an increase of intrinsic defects. Since the doping efficiency is directly related with the improvement of the film electric properties, the optimization of the doping process is one of the keys to achieve better and competitive transparent electrodes for many applications.

\section{ACKNOWLEDGMENTS}

Authors gratefully acknowledge financial support from the Spanish Ministerio de Ciencia e Innovación through Project Nos. TEC2007-60996, MAT2008-06858-C02-02, MAT200806330, TEC2010-16700, and FUNCOAT-CSD2008-00023CONSOLIDER INGENIO, from the Sonderforschungsbereich, under Grant No. SFB 762, Functionality of Oxide Interfaces, and from the European Commission through FEDER funds. Technical support from S.C.A.I., (University of Málaga) and Servicio de Microscopia (ICMM-CSIC) and Centro Nacional de Microscopía Luis Bru (UCM) is gratefully acknowledged.

${ }^{1}$ Ü. Özgür, Y. I. Alivov, C. Liu, A. Teke, M. A. Reshchikov, S. Doğan, V. Avrutin, S.-J. Cho, and H. Morkoç, J. Appl. Phys. 98, 041301 (2005).

${ }^{2}$ T. Minami, Semicond. Sci. Technol. 20, S35 (2005).

${ }^{3}$ C. G. Grandqvist, Sol. Energy Mater. Sol. Cells 91, 1529-1598 (2007).

${ }^{4}$ P. Nunes, E. Fortunato, P. Tonello, F. Braz Fernandes, P. Vilarinho, and R. Martins, Vacuum 64, 281 (2002).

${ }^{5}$ T. Minami, Thin Solid Films 516, 5822 (2008).

${ }^{6}$ C. Agashe, O. Kluth, J. Hüpkes, U. Zastrow, B. Rech, and M. Wuttig, J. Appl. Phys. 95, 1911 (2004).

${ }^{7}$ D. J. Lee, H. M. Kim, J. Y. Kwon, H. Choi, S. H. Kim, and K. B. Kim, Adv. Funct. Mater. 21, 448 (2011).

${ }^{8}$ K. H. Kim, K. C. Park, and D. Y. Ma, J. Appl. Phys. 81, 7764 (1997).

${ }^{9}$ K. K. Kim, J. H. Song, H. J. Jung, W. K. Choi, S. J. Park, and J. H. Song, J. Appl. Phys. 87, 3573 (2000).

${ }^{10}$ A. Miyake, T. Yamada, H. Makino, N. Yamamoto, and T. Yamamoto, Thin Solid Films 517, 1037 (2008).

${ }^{11}$ C. H. Tseng, C. H. Huang, H. C. Chang, D. Y. Chen, C. P. Chou, and C. Y. Hsu, Thin Solid Films 519, 7959 (2011).

${ }^{12}$ See http://public.wsu.edu/ scudiero/index.html for information on XPSpeak software package.

${ }^{13}$ M. Gabás, P. Díaz-Carrasco, F. Agulló-Rueda, P. Herrero, A. R. LandaCánovas, and J. R. Ramos-Barrado, Sol. Energy. Mater. Sol. Cells 95, 2327 (2011).

${ }^{14}$ L. J. van der Pauw, Philips. Tech. Rev. 20, 220 (1958).

${ }^{15}$ S. Steplecaru, Ph.D. thesis, Universidad Autónoma de Madrid, 2012.

${ }^{16}$ X. Yu, J. Ma, F. Ji, Y. Wang, X. Zhang, C. Cheng, and H. Ma, J. Cryst. Growth 274, 475 (2005).

${ }^{17}$ J. G. Lu, Z. Z. Ye, Y. J. Zeng, L. P. Zhu, L. Wang, J. Yuan, B. H. Zhao, and Q. L. Liang, J. Appl. Phys. 100, 073714 (2006).

${ }^{18}$ Z. Yang, D. C. Look, and J. L. Liu, Appl. Phys. Lett. 94, 072101 (2009).

${ }^{19}$ H. Serier, A. Demourgues, and M. Gaudon, Inorg. Chem. 49, 6853 (2010).

${ }^{20}$ S. D. Shinde, A. V. Deshmukh, S. K. Date, V. G. Sathe, and K. P. Adhi, Thin Solid Films 520, 1212 (2011).

${ }^{21}$ A. Klein and F. Säuberlich, in Transparent Conductive Zinc Oxide. Basics and Applications in Thin Film Solar Cells, Springer Series in Materials Science, edited by K. Ellmer, A. Klein, and B. Rech (Springer, Germany, 2008), Chap. 4.

${ }^{22}$ F. Decremps, J. Pellicer-Porres, A. M. Saitta, J.-C. Chervin, and A. Polian, Phys. Rev. B 65, 092101 (2002). 
${ }^{23}$ M. Millot, R. Tena-Zaera, V. Muñoz-Sanjosé, J.-M. Broto, and J. González, Appl. Phys. Lett. 96, 152103 (2010).

${ }^{24}$ F. J. Manjón, B. Marí, J. Serrano, and A. H. Romero, J. Appl. Phys. 97, 053516 (2005).

${ }^{25}$ S. K. Sharma and G. J. Exarhos, Solid State Phenom. 55, 32 (1997).

${ }^{26}$ M. Gabás, N. T. Barrett, J. R. Ramos-Barrado, S. Gota, T. C. Rojas, and M. C. López-Escalante, Sol. Energ. Mater. Sol. Cells 93, 1356 (2009).

${ }^{27}$ E. Ochoa, M. Gabás, S. Bijani, S. Palanco, A. R. Landa-Cánovas, P. Herrero, F. Agulló-Rueda, P. Díaz-Carrasco, and J. R. Ramos-Barrado, in Proceedings of 38th IEEE PVSC, Austin (Texas), 2012.

${ }^{28}$ B. K. Sharma and N. Khare, J. Phys. D: Appl. Phys. 43, 465402 (2010).

${ }^{29}$ A. B. M. A. Ashrafi, N. T. Binh, B. P. Zhang, and Y. Segawa, Appl. Phys. Lett. 84, 2814 (2004).

${ }^{30}$ J. Cui, J. Phys. Chem. C 112, 10385 (2008).

${ }^{31}$ P. Romero-Gómez, J. Toudert, J. R. Sánchez-Valencia, A. Borrás, A. Barranco, and A. R. González-Elipe, J. Phys. Chem. C 114, 20932 (2010).
${ }^{32}$ V. Bhosle, A. Tiwari, and J. Narayan, Appl. Phys. Lett. 88, 032106 (2006).

${ }^{33}$ V. Bhosle, A. Tiwari, and J. Narayan, J. Appl. Phys. 100, 033713 (2006).

${ }^{34}$ R. D. Shannon, Acta Crystallogr. 32, 751 (1976).

${ }^{35} \mathrm{~K}$. Ellmer, in Transparent Conductive Zinc Oxide. Basics and Applications in Thin Film Solar Cells, Springer Series in Materials Science, edited by K. Ellmer, A. Klein, and B. Rech (Springer, Germany, 2008), Chap. 2.

${ }^{36}$ A. R. Landa-Cánovas, J. Nilsson, S. Hansen, K. Stahl, and A. Andersson, J. Solid State Chem. 116, 369 (1995).

${ }^{37}$ A. R. Landa-Cánovas, F. J. García-García, and S. Hansen, Catal. Today 158, $156(2010)$

${ }^{38}$ J. U. Brehm, M. Winterer, and H. Hahn, J. Appl. Phys. 100, 064311 (2006).

${ }^{39}$ R. Noriega, J. Rivnay, L. Goris, D. Kalblein, H. Klauk, K. Kern, L. M. Thompson, A. C. Palke, J. F. Stebbins, J. R. Jokisaari, G. Kusinski, and A. Salleo, J. Appl. Phys. 107, 074312 (2010). 